\title{
Impactos das rendas petrolíferas no crescimento econômico dos municípios no Espírito Santo
}

\author{
Sávio Bertochi Caçador ${ }^{1}$ \\ Edson Zambon Monte ${ }^{2}$
}

\begin{abstract}
Resumo: Em 1997, o Brasil aprovou a Lei no 9.478, estabelecendo novos critérios de cálculo e de distribuição de royalties para os municípios produtores ou afetados pela atividade petrolífera. Com o revigoramento dessa atividade no Espírito Santo no final dos anos 1990 e início dos anos 2000, torna-se importante estudar os impactos causados pelas participações governamentais nas cidades desse estado. Portanto, estimou-se um modelo empírico para avaliar os impactos locais dos royalties no crescimento do PIB per capita dos municípios capixabas considerados produtores de petróleo. Os resultados da estimativa permitiram confirmar a chamada "maldição dos recursos naturais", mostrando que os PIBs dessas cidades não foram afetados pelos royalties.
\end{abstract}

JEL: H27, Q32, R11.

Palavras-chave: Rendas do Petróleo, Crescimento Econômico, Espírito Santo.

\section{Impacts of oil rents on economic growth in the municipalities of Espírito Santo}

\footnotetext{
Abstract: In 1997, Brazil approved the Law 9.478, setting new criteria of the calculation and for distribution of oil royalties among the municipal districts. With the revival of this activity in Espírito Santo in late 1990 and early 2000, it becomes important to study the impacts caused by government shares in the State's cities. Therefore, one has estimated an empirical model for assessing the local impacts of 
CAÇADOR, B, S.; MONTE, E. Z. Impactos das rendas petrolíferas no crescimento econômico...

royalties in the growth of GDP per capita of Espírito Santo's municipalities considered oil producers. The results of estimation confirm the "natural resource curse", showing that the GDP of these cities were not affected by oil royalties.

Keywords: Oil Rents, Economic Development, State of Espírito Santo.

JEL: H27, Q32, R11.

\section{Introdução}

O Brasil reformulou o aparato institucional de sua indústria petrolífera em meados dos anos 1990, estabelecendo, dentre outras coisas, novos critérios para as chamadas participações governamentais, isto é, pagamentos a serem realizados pelos concessionários de atividades de exploração e produção de petróleo e de gás natural. Assim, a lógica inerente a essa legislação é que as regiões direta ou indiretamente afetadas pelas atividades petrolíferas recebam maior parte da compensação financeira repassada pelo governo federal.

Para o Espírito Santo em específico, esse novo marco regulatório da indústria petrolífera trouxe pelo menos dois impactos. No campo estritamente econômico, a produção de petróleo e gás natural ressurgiu no estado a partir do final da década de 1990. Com descobertas anunciadas pela Petrobrás e empresas estrangeiras, o estado se tornou a $2^{\mathrm{a}}$ maior província petrolífera do país, atrás apenas do Rio de Janeiro. O outro impacto se deu nas finanças públicas dos governos estadual e municipais. A título de exemplo, em Presidente Kennedy, no litoral sul capixaba, a razão entre royalties + participações especiais sobre a receita municipal foi de quase 80\% em 2010 (Freire e Magenta, 2011), a maior dentre todos os municípios brasileiros.

Dessa forma, torna-se importante estudar os impactos provocados pelas participações governamentais nos municípios espírito-santenses. Assim, estimou-se um modelo empírico para investigar se as rendas petrolíferas distribuídas contribuíram para o crescimento de seus Produtos Internos Brutos (PIBs) per capita desde o final dos anos 1990 até os anos 2000. Vale dizer que, segundo ANP (2011), desde 2005 todas as cidades do estado recebem royalties, sendo que 15 destas auferem uma quantidade maior desse recurso por serem produtores ou confrontantes com poços de petróleo ${ }^{1}$.

Cabe ressaltar que Postali (2007) já fez análise similar à proposta desta pesquisa para o conjunto dos municípios brasileiros, que serviu de base metodológica para o presente artigo. No entanto, acredita-se que o Espírito Santo precisa de uma investigação específica sobre sua realidade, dado que a distribuição das rendas petrolíferas é heterogênea tanto entre estados como entre cidades, o que é ressaltado pelos próprios autores citados anteriormente.

1 Esses municípios são: Aracruz, Anchieta, Conceição da Barra, Guarapari, Fundão, Itapemirim, Jaguaré, Linhares, Marataízes, Piúma, Presidente Kennedy, São Mateus, Serra, Vila Velha e Vitória. Esta classificação também é coerente com o relatório do MPES (2011) sobre os royalties recebidos por essas cidades. 
O restante do artigo se divide em cinco seções. A próxima resume os pontos marcantes do atual marco regulatório das participações governamentais, bem como apresenta os principais estudos sobre os impactos das rendas petrolíferas no Brasil e no Espírito Santo. A terceira seção apresenta os dados mais relevantes sobre a atividade petrolífera e as participações governamentais no estado e seus municípios. A quarta seção explana a bases de dados, a técnica e os resultados do modelo estimado nesse trabalho. Na última seção, por sua vez, tecem-se as considerações finais.

\section{Referencial ${ }^{2}$}

\subsection{Legislação das participações governamentais}

Nos anos 1990, o marco regulatório da indústria petrolífera brasileira foi reformulado. O processo teve início com a Emenda Constitucional $n^{\circ}$ 9/95, que quebrou o monopólio estatal na exploração e refino de petróleo. Em 1997, o Congresso Nacional aprovou a Lei ${ }^{0}$ 9.478/97 - conhecida como "Lei do Petróleo". Esta lei estabeleceu uma nova lógica para as participações governamentais, que foram definidas pelo Decreto $\mathrm{n}^{0} 2.705$, de 3 de agosto de 1998 - conhecido também como Decreto das Participações Governamentais. Tais participações, que devem estar contidas no contrato de concessão e previstas no edital de licitação, são: i) bônus de assinatura; ii) royalties; iii) participação especial; e, iv) pagamento pela ocupação ou retenção de área.

O bônus de assinatura corresponde ao montante ofertado pelo licitante vencedor na proposta para obtenção da concessão, que não pode ser inferior ao valor mínimo fixado pela Agência Nacional do Petróleo (ANP) no edital de licitação. O valor do bônus de assinatura do licitante vencedor, que deve refletir o grau de atratividade econômica do bloco licitado, tem que ser pago no ato da assinatura do respectivo contrato de concessão e em parcela única. Segundo o Artigo 15 da Lei 9.748/97, o montante arrecadado com o bônus de assinatura será destinado ao Tesouro Nacional e constituirá em receita da ANP.

Os royalties constituem compensação financeira devida pelos concessionários à União, a serem pagos mensalmente, a partir do mês em que um determinado campo começar a produzir. O seu valor será determinado multiplicando-se o equivalente a $10 \%$ do volume total da produção mensal de petróleo e gás natural do campo pelos seus respectivos preços de referência. Com relação ao petróleo é adotado, como preço de referência, a média ponderada dos preços de venda (sem tributos) praticados pela empresa no respectivo mês ou um preço mínimo estabelecido pela ANP, aplicando-se o que for maior. No caso do gás natural, o preço de referência será igual à média ponderada dos preços de venda (sem tributos) acordados nos contratos de fornecimento entre 
concessionário e compradores, deduzidas as tarifas relativas ao transporte do gás até os pontos de entrega.

No entanto, a alíquota dos royalties pode variar até um mínimo de 5\% sobre o volume de produção do campo. Para fazer isto a ANP leva em conta riscos geológicos, expectativas de produção e outros fatores como produção em áreas remotas, produção de gás natural não associado ou de petróleo pesado, dificuldades operacionais, inexistência de infraestrutura para escoar a produção, distância até o mercado, etc. (Barbosa, 2001, p. 20). Cabe lembrar que quando a parcela do valor dos royalties previstos no contrato de concessão equivaler a esse mínimo de $5 \%$, a sua distribuição seguirá o estabelecido na Lei $7.990 / 89$.

A participação especial constitui, por seu turno, compensação financeira extraordinária devida pelos concessionários nos casos de grande volume de produção ou de grande rentabilidade do campo. A sua apuração será feita mediante aplicação de alíquotas progressivas sobre a receita líquida trimestral de cada campo. Tais alíquotas variam em função da localização da lavra, do número de anos de produção e do respectivo volume de produção trimestral fiscalizada. De acordo com Postali (2002; p. 96) o princípio da participação especial é permitir ao governo obter uma parcela maior da renda dos projetos mais lucrativos. As suas alíquotas podem ser de 0\%, 10\%, 20\%, 30\%, 35\% e $40 \%$.

Finalmente, a Lei 9.478/97 prevê uma quarta modalidade de participação governamental, o pagamento pela ocupação ou retenção de área do bloco. Este valor deve ser pago anualmente pelos concessionários, a partir da data de assinatura do contrato de concessão, disposto no edital de licitação e no próprio contrato de concessão. Os valores unitários por quilômetro quadrado ou fração da área de concessão devem ser fixados no edital e no contrato de concessão, sendo aplicáveis às fases de exploração, produção e desenvolvimento.

Por último, cabe tecer algumas considerações sobre a aplicação dos royalties e participações especiais originárias das atividades petrolíferas, pois somente essas duas modalidades de renda petrolífera são distribuídos entre os entes da federação brasileira. Em primeiro lugar, a análise da evolução legal das indenizações ou compensações financeiras petrolíferas demonstra que a questão da aplicação dos recursos recebeu pouca atenção ao longo do tempo. Isto fica evidente quando se constata que até 1986 não existia instrumento legal que se referia ao controle e a fiscalização de tais recursos. Foi somente a partir deste ano, em que foi promulgada a Lei 7.525/86, que a fiscalização passou a ser feita pelo Tribunal de Constas da União (TCU). Desta forma, o gestor público possuía total liberdade para gastar tais receitas extraordinárias, desde que observado o interesse público.

Com a edição da Lei 9.478/97 a situação se agravou, uma vez que a abrangência 
da aplicação dos recursos foi ampliada, pois não fez nenhuma referência acerca da destinação dos recursos das participações governamentais ${ }^{3}$ (royalties + participações especiais). Entretanto, permanecem vigentes as restrições impostas pelo Artigo $8^{\circ}$ da Lei 7.990/89, que veda a aplicação dos recursos em pagamento de dívidas e no quadro permanente de pessoal.

Esta flexibilização na aplicação dos recursos das participações governamentais (royalties + participações especiais) foi dilatada ainda mais em 2001, com a publicação da Medida Provisória $n^{0}$ 2.103. O Artigo 16 desta autoriza a União a adquirir dos Estados créditos relativos às participações governamentais. Em troca, a União utilizaria em pagamento Certificados Financeiros do Tesouro, que seriam obrigatoriamente utilizados pelos governos estaduais para o pagamento de dívidas com a União e suas entidades, ou na capitalização dos fundos de previdência, a critério do Ministério da Fazenda.

Vale destacar também que a descoberta de hidrocarbonetos na camada pré-sal tem suscitado a discussão sobre alterações nos critérios de distribuição das participações governamentais. Mais precisamente, a discussão teve início com a emenda $387 / 2009$ ao projeto de lei brasileira $n^{0} 5.938$ de 2009, que propõe modificações no marco regulatório para a exploração de petróleo na camada pré-sal. Conhecida como emenda Ibsen Pinheiro, basicamente ela propõe que a União fique com $40 \%$ dos royalties e $50 \%$ da participação especial da produção de petróleo em mar, ao passo que o restante dos recursos seria dividido entre estados e municípios, seguindo as regras do Fundo de Participação dos municípios e dos estados.

Depois de vetada a emenda Ibsen Pinheiro, a discussão evoluiu para o projeto de lei 2.565/2011. Tal projeto determina a redução de 50\% para $42 \%$ da parcela da União na participação especial. Em relação aos royalties, o projeto propõe uma redução de $30 \%$ para $20 \%$ na fatia destinada ao governo federal. Para compensar o governo estadual, foi proposto que, a partir de 2013, a União receba uma compensação na participação especial de 1\% por ano, até chegar a 46\% em 2016. Já para os estados produtores, a sua parcela de royalties seria reduzida de $26,25 \%$ para $20 \%$ e a participação especial cairia de $40 \%$ para 20\%. Contudo, o Deputado Carlos Zarattini apresentou um substitutivo a emenda 2.565/11, permitindo a manutenção, até 2020, da receita auferida por estados e municípios produtores em 2011. ${ }^{4}$

\subsection{Revisão da literatura ${ }^{5}$}

Em função do montante crescente de recursos e da importância cada vez maior

3 Doravante entendido como royalties + participações especiais, sendo chamado simplesmente de royalties. 4 Essas propostas ainda estão em discussão no Congresso Nacional. De qualquer forma, ressalta-se que não é o propósito deste trabalho discutir os impactos das alterações de critérios das participações governamentais sobre o Espírito Santo e seus municípios.

5 Para o caso do Brasil, baseado em Postali e Nishijima (2011). 
que os mesmos representam para muitas regiões do país, alguns trabalhos têm estudado a relação entre os royalties recebidos por uma localidade e seu grau de desenvolvimento social. Leal e Serra (2002), por exemplo, analisam a aplicação das receitas de royalties em municípios do norte fluminense. Os autores concluem que os municípios contemplados com essas receitas, na forma da nova lei, destinaram recursos para investimentos em volume superior à média do estado, mas o valor deste investimento tem se mostrado sistematicamente menor que o montante de royalties recebido.

Sobre o caso específico do município de Campos dos Goytacazes - o maior beneficiário de rendas do petróleo, em termos brutos -, Navarro (2003) avaliou que seu Índice de Desenvolvimento Humano (IDH) evoluiu ligeiramente acima de cidades similares ao longo da década de 1990. Este município também aumentou seus investimentos em saneamento e em infraestrutura, mas numa proporção menor do que as rendas recebidas de petróleo.

Já Costa Nova (2005) examinou diversos indicadores sociais de alguns municípios baianos que receberam valores expressivos de royalties. A principal conclusão é que, apesar da situação orçamentária favorável, essas cidades não expandiram significativamente seus indicadores sociais quando comparados com municípios que não têm direito a estes recursos.

Bregman (2007) investigou a relação entre as receitas de royalties e as despesas de capital em municípios dependentes de recursos do petróleo para o período de 1999 a 2005 em todo o país. As conclusões apontaram que os municípios cujos orçamentos mais dependem de rendas do petróleo investiram em igual proporção ao ingresso de tais receitas.

Diferentemente dos trabalhos anteriores, Postali (2007) avaliou o impacto das rendas petrolíferas sobre o crescimento econômico dos municípios beneficiados pela nova legislação no período 1996/2004. Para isso, ele utilizou o estimador de diferenças-em-diferenças (DD) (Meyer, 1995), cuja intuição é estudar o impacto de determinado evento exógeno sobre o desempenho de um grupo (os beneficiários de royalties), comparando-o com o desempenho de outro grupo não afetado pelo evento (os que não se beneficiaram de royalties). Os resultados confirmam a chamada "maldição dos recursos naturais" da literatura mundial, mostrando que os municípios contemplados com royalties cresceram menos que os municípios que não receberam tais recursos. Em geral, para cada 1\% adicional de royalties observa-se uma redução de cerca de 0,06 ponto percentual na taxa de crescimento do município.

Caselli e Michaels (2009) elaboraram um estudo acerca dos efeitos dos royalties sobre indicadores sociais de localidades brasileiras, assim como sobre suas despesas. As principais conclusões foram: 1) as receitas extraordinárias do petróleo de fato geram algum aumento em despesas ligadas à qualidade social, como infraestrutura urbana, saúde e educação; e, 2) os indicadores sociais não responderam satisfatoriamente ao aumento destes recursos. 
O estudo acadêmico mais recente sobre o tema é o de Postali e Nishijima (2011). Eles investigaram se os royalties distribuídos sob a lei 9.478/97 contribuíram para a melhoria dos indicadores sociais dos municípios contemplados, em relação à média nacional, no período de 2000 a 2007. Os resultados mostram que as rendas do petróleo não produziram impactos significativos nos indicadores sociais de saúde e de educação dos municípios beneficiados, mas geraram efeitos negativos sobre seus setores formais de trabalho.

Outro texto sobre o assunto é relatório da Macroplan (2012). Ele teve por objetivo analisar indicadores econômicos, sociais e de finanças públicas de 25 municípios, sendo 16 do Rio de Janeiro, quatro do estado de São Paulo e cinco do Espírito Santo, que recebem grandes volumes de recursos de royalties na década de 2000, e traçar perspectivas de desenvolvimento com a utilização destes recursos. Segundo o texto, cerca de 70\% do valor dos royalties e participações especiais transferidos para os municípios concentram-se nessas 25 cidades.

Além disso, foi realizada uma pesquisa de campo em seis "cidades petróleo": Rio das Ostras (RJ), São Sebastião (SP), Linhares (ES), São João da Barra (RJ), Macaé (RJ) e Presidente Kennedy (ES). ${ }^{6}$ As principais constatações dessa pesquisa foram:

i) Paradoxo da abundância: aumento de recursos com permanência de baixos índices de qualidade de vida;

ii) O efeito do "primo-rico": aumento da demanda dos municípios vizinhos, com pouca oferta de serviços públicos, gera sobrecarga, principalmente, nos serviços de saúde e educação;

iii) Nenhuma cidade apresentou planos de longo prazo para o emprego dos royalties e muito menos para a eventualidade de flutuações cíclicas ou declínio permanente;

iv) Em muitos casos, a impossibilidade de se promover contratações com os recursos dos royalties é contornada através da terceirização, o que gera aumento de gastos com pessoal e custeio;

v) As evidências empíricas indicam que a utilização destes recursos não produziu o retorno esperado no que diz respeito ao desenvolvimento dos municípios e melhoria da qualidade de vida da população e não promove a justiça intergeracional.

No caso do Espírito Santo, são poucos os estudos sobre os impactos dos royalties no bem-estar ou no crescimento econômico de seus municípios. Grassi e Caçador (2007), por exemplo, analisaram o impacto das rendas petrolíferas sobre as receitas e despesas do governo estadual e das seis localidades ca- 
pixabas que mais receberam esses recursos entre 2000 e 2005. Quanto ao governo estadual, notou-se que os royalties ainda não representavam parcela significativa do seu orçamento. Mesmo assim, isso não impediu que fosse feito um acordo para pagamento de dívidas com o governo federal com base em receitas futuras desses recursos. No que tange aos municípios, comprovou-se que em alguns deles já existia uma dependência razoável, embora as despesas de capital não tenham crescido na mesma proporção.

Por outro lado, Ribeiro et al. (2010) estudaram os efeitos dos royalties no PIB dos 78 municípios capixabas entre 1999 e 2004. Usando a metodologia de dados em painel equilibrado, mostraram que as rendas petrolíferas não impactaram os PIBs municipais.

\section{Atividade petrolífera e royalties no Espírito Santo: dados relevantes}

A presente seção apresenta, de forma sucinta, os principais dados sobre a produção de gás natural e petróleo, bem como a distribuição de royalties aos municípios capixabas. O objetivo é comparar a evolução, entre 2000 e 2009 - período tomado como base para o presente estudo -, do Espírito Santo relativamente ao Rio de Janeiro, a maior província petrolífera do país, e ao Brasil.

Nessa linha, dados da ANP (2011) no gráfico 1 mostram que a produção de gás natural em território capixaba era de 317 milhões de $\mathrm{m}^{3}$ em 2000, cerca de $5,5 \%$ da carioca e 2,4\% da nacional. Já em 2009, o estado alcançou a marca de 1,1 bilhões de $\mathrm{m}^{3}$ produzidos, representando 10,3\% da produção do Rio de Janeiro e 5,1\% da brasileira. Tal produção cresceu vertiginosamente no período 2000-2009, a uma média anual de 23,9\%, conforme gráfico 2. Esse percentual supera, em muito, a expansão de 8,3\% do Rio de Janeiro e 5,9\% da brasileira. Vale destacar que, a partir de 2006, o aumento da produção capixaba se desloca da nacional e da carioca, basicamente por conta da inauguração da Plataforma de Peroá e da Unidade de Tratamento de Gás de Cacimbas.

Dando continuidade, estatísticas da ANP (2011) no gráfico 3 mostram que a produção de petróleo no Espírito Santo era de 4,7 milhões de barris em 2000, representando cerca de $1,3 \%$ da carioca e $1 \%$ da nacional. Já em 2009, o estado atingiu o valor de 35,9 milhões de barris produzidos, 5,9\% da produção do Rio de Janeiro e 5,1\% da brasileira. A produção local de petróleo cresceu exponencialmente entre 2000 e 2009, a uma média anual de $67 \%$, segundo o gráfico 4. Esse percentual é bem superior a expansão de 6,9\% do Rio de Janeiro e 5,8\% da brasileira. Salienta-se que, a partir de 2002, o aumento da produção capixaba se desloca da nacional e da carioca, sobretudo em razão do início da produção em águas profundas no campo de Jubarte, ainda em 2002, e do começo da produção do campo de Golfinho, em 2006. 
GRÁFICO 1: PRODUÇÃO DE GÁS NATURAL, EM MILHÕES DE M³ (2000-2009)

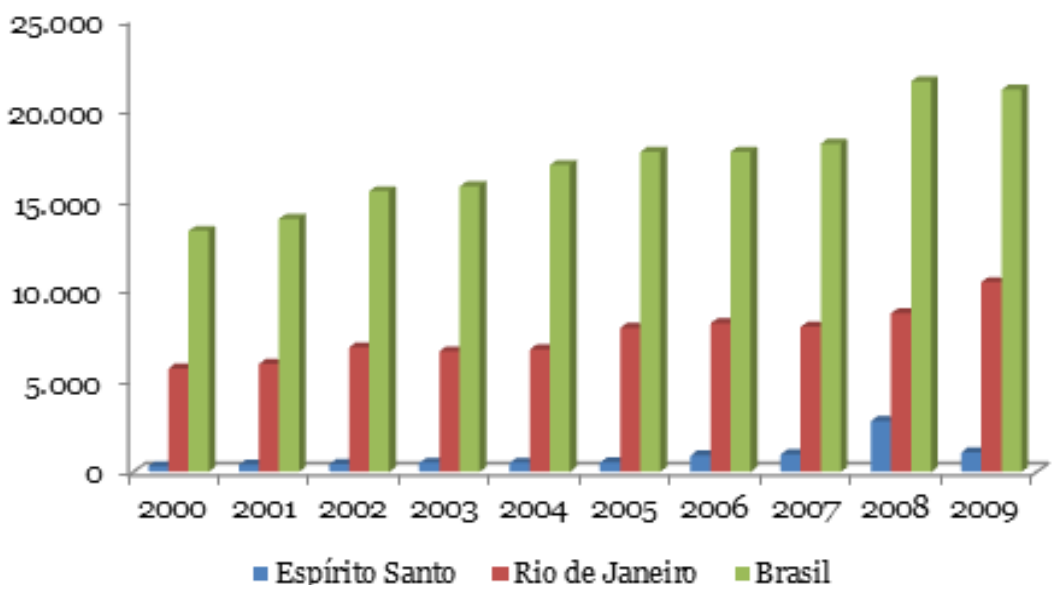

Fonte: ANP (2011).

GRÁFICO 2: VARIAÇÃO DA PRODUÇÃO DE GÁS NATURAL (20002009), EM NÚMERO-ÍNDICE $2000=100$

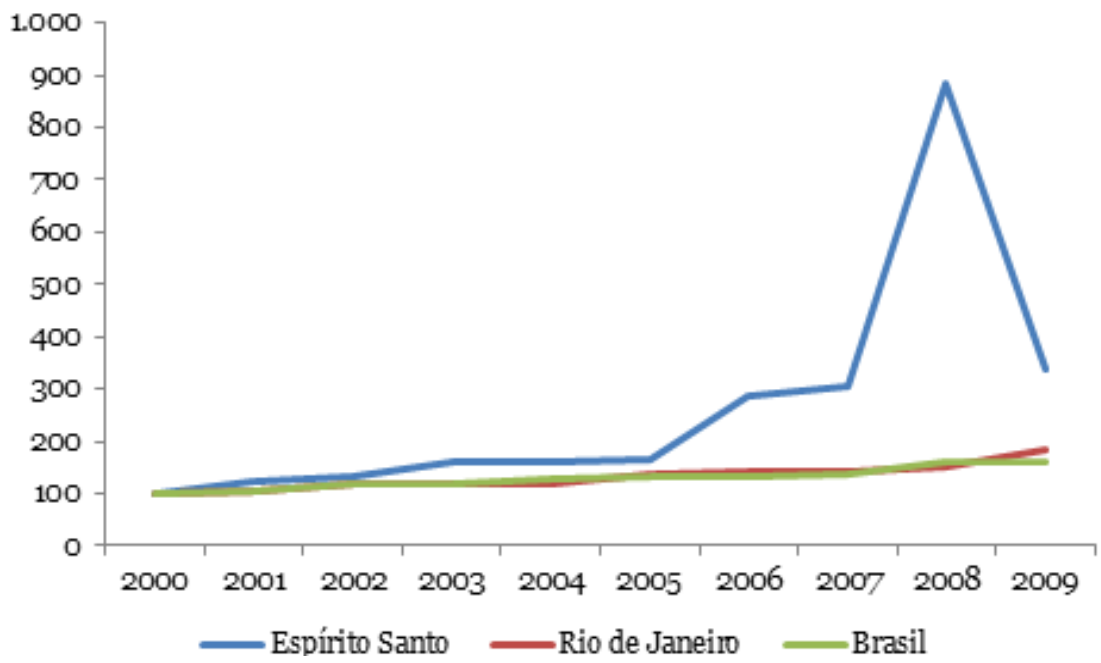

Fonte: ANP (2011). 


\section{GRÁFICO 3: PRODUÇÃO DE PETRÓLEO, EM MIL BARRIS (2000-2009)}

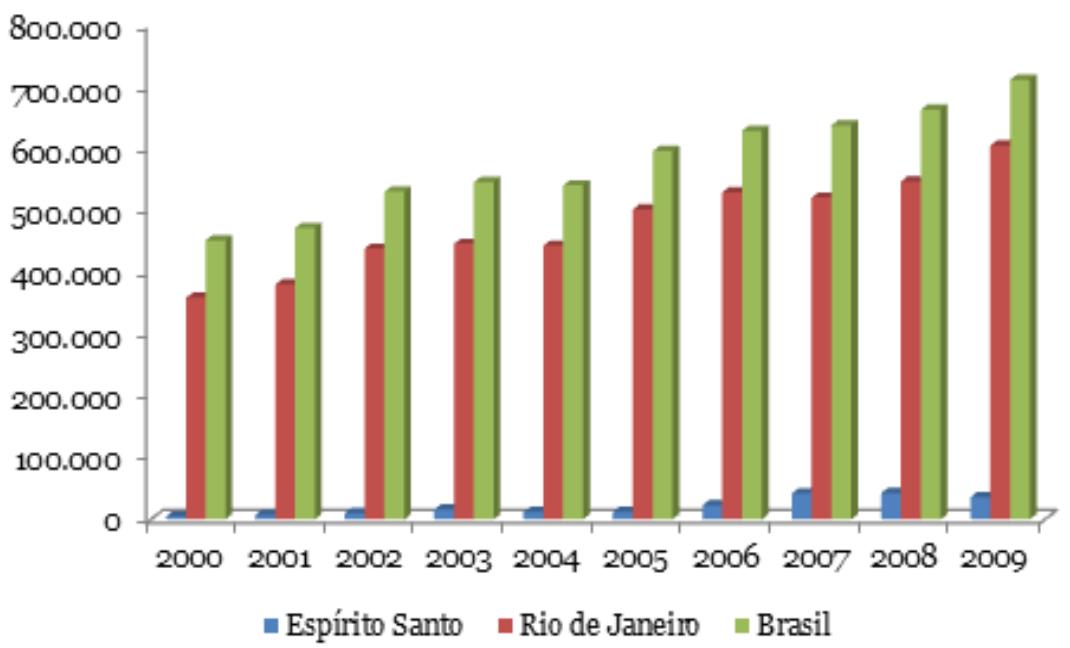

Fonte: ANP (2011).

GRÁFICO 4: VARIAÇÃO DA PRODUÇÃO DE PETRÓLEO (2000-2009) EM NÚMERO-ÍNDICE $2000=100$

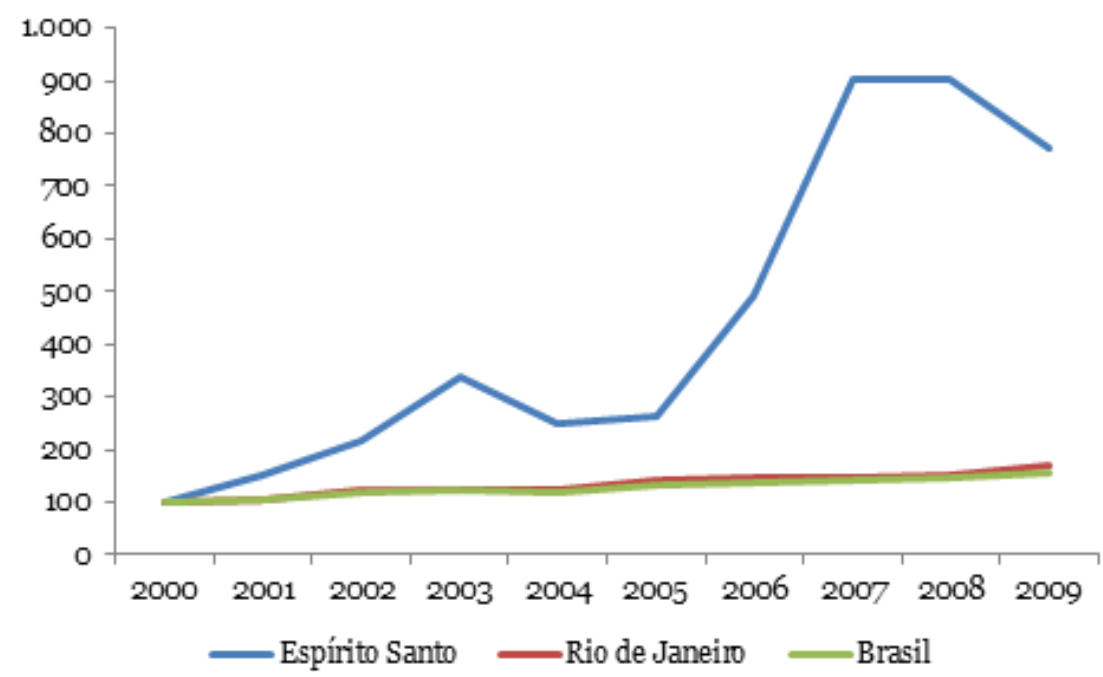

Fonte: ANP (2011) 
GRÁFICO 5: DISTRIBUIÇÃO DE ROYALTIES AOS MUNICÍPIOS (20002009), EM R\$ MIL DEFLACIONADOS PELO IPCA DE 2000

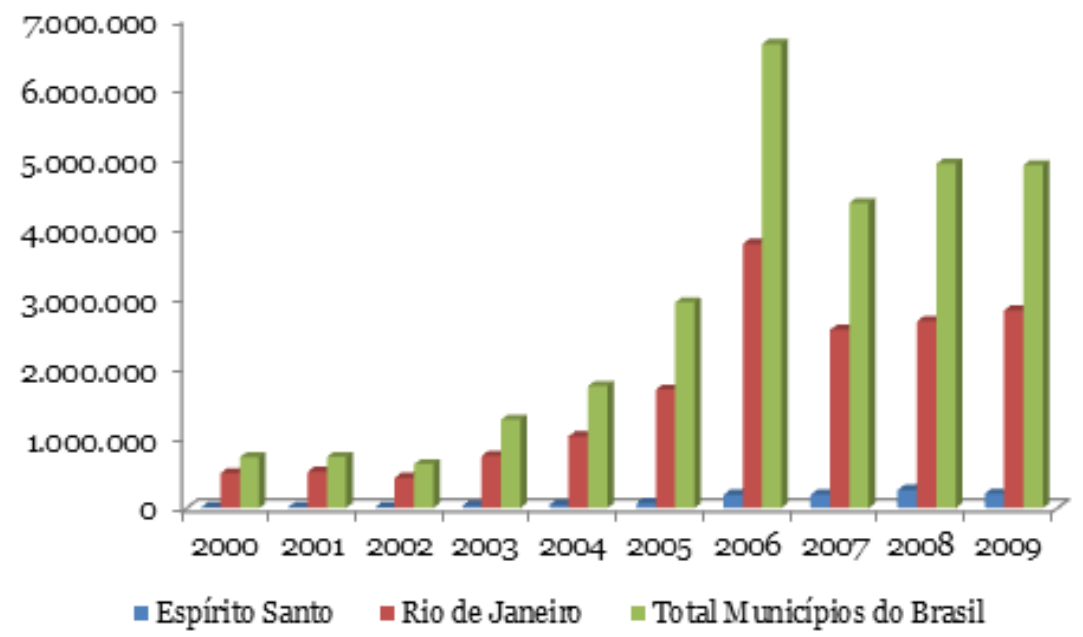

Fonte: ANP (2011).

GRÁFICO 6: VARIAÇÃO DA DISTRIBUIÇÃO DE ROYALTIES AOS MUNICÍPIOS (2000-2009),EM NÚMERO-ÍNDICE 2000=100

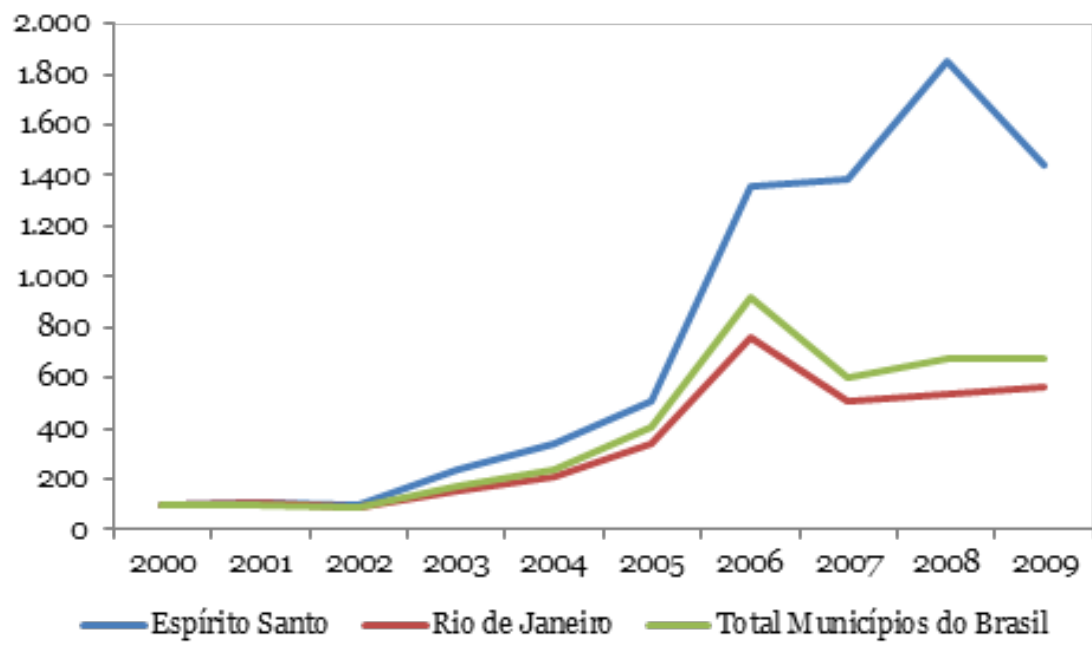

Fonte: ANP (2011). 
CAÇADOR, B, S.; MONTE, E. Z. Impactos das rendas petrolíferas no crescimento econômico...

Em função da crescente produção de gás e óleo no Espírito Santo, a distribuição de royalties para os seus municípios também aumentou significativamente. Assim, o gráfico 5 mostra que os recursos distribuídos às cidades capixabas passaram de R \$ 10 milhões, em 2000, para R \$ 194 milhões, em 2009. Apesar disso, esse último valor representava apenas 7,2\% do montante repassado aos municípios do Rio de Janeiro e 4,2\% do total das cidades brasileiras. Ademais, o gráfico 6 mostra que as rendas petrolíferas transferidas às localidades capixabas cresceram substancialmente entre 2000 e 2009, a uma média anual de 134\%, muito superior ao aumento da produção de gás e óleo. Esse percentual é superior a expansão de 46,5\% e 57,6\% para as cidades do Rio de Janeiro e do Brasil, respectivamente.

Finalmente, a tabela 1 apresenta os valores de royalties recebidos pelos municípios capixabas entre os anos de 2000 e de 2009. Tal tabela explícita a heterogeneidade da distribuição desses recursos: i) as cidades produtoras de petróleo e gás ou confrontantes com poços concentraram 88,4\% do montante auferido em 2009; e, ii) somente três localidades (Presidente Kennedy, Linhares e São Mateus) responderam por $62,2 \%$ do total recebido pelas cidades espírito-santenses.

\section{Procedimentos empíricos}

\subsection{Metodologia e base de dados}

Do ponto de vista metodológico, o trabalho foi baseado Postali (2007), que analisou o caso dos municípios brasileiros no período 1996/2004 usando o estimador de diferenças-em-diferenças (DD) (Meyer, 1995), conforme resenhado na seção 2.2. No caso em questão, deseja-se comparar a evolução da taxa de crescimento do produto per capita dos municípios produtores de petróleo que passaram a receber grandes quantias de royalties a partir de 2005 - classificados como grupo de tratamento - com os municípios que não são produtores, mas que receberam royalties em menor quantidade que o grupo anterior - classificados como grupo de controle.

Operacionalmente, seja $y_{i t}$ a variável dependente (taxa de crescimento do PIB per capita) do município $i$ no período $t$, tal que $t=0$ indica antes do tratamento (até 2004) e $t=1$ após 2005 (inclusive). Dessa forma, a análise em foco compreenderá o período 2000/2004 e 2005/2009.

A justificativa para adotar tal período reside no seguinte ponto: conforme os dados exibidos na seção 3, a produção capixaba de petróleo e gás natural passou a ganhar maior escala depois de 2004, quando começou a produção em alguns grandes poços. Em função disso, os royalties destinados aos municípios capixabas, sobretudos aqueles confrontantes com poços, vem crescendo substancialmente desde 2005 . 
TABELA 1: ROYALTIES + PARTICIPAÇÕES ESPECIAIS RECEBIDOS PELOS MUNICÍPIOS DO ES (2000/2009), A PREÇOS CONSTANTES (IPCA $2000=100$ )

\begin{tabular}{|c|c|c|c|c|}
\hline Beneficiário & $\begin{array}{c}2000 \\
\text { (R\$ mil) }\end{array}$ & $\begin{array}{l}\text { Part. Relativa } \\
\text { em } 2000(\%)\end{array}$ & $\begin{array}{c}2009 \\
\text { (R\$ mil) }\end{array}$ & $\begin{array}{l}\text { Part. Re- } \\
\text { lativa em } \\
2009(\%)\end{array}$ \\
\hline Anchieta & 2 & 0,02 & 2.063 & 1,06 \\
\hline Aracruz & $\mathrm{o}$ & $\mathrm{O}, \mathrm{OO}$ & 11.467 & 5,89 \\
\hline Conceição da Barra & 337 & 3,25 & 1.239 & 0,64 \\
\hline Fundão & o & 0,00 & 3.108 & 1,60 \\
\hline Guarapari & 1 & $\mathrm{O}, \mathrm{O} 1$ & 487 & 0,25 \\
\hline Itapemirim & o & 0,00 & 11.923 & 6,13 \\
\hline Jaguaré & 402 & 3,87 & $4 \cdot 975$ & 2,56 \\
\hline Linhares & 4.684 & 45,16 & 28.529 & 14,66 \\
\hline Marataízes & o & 0,00 & 4.255 & 2,19 \\
\hline Piúma & o & 0,00 & 616 & 0,32 \\
\hline Presidente Kennedy & 458 & 4,42 & 79.189 & 40,70 \\
\hline São Mateus & 2.651 & 25,56 & 13.256 & 6,81 \\
\hline Serra & o & 0,00 & 6.504 & 3,34 \\
\hline Vila Velha & 1 & 0,01 & 3.034 & 1,56 \\
\hline Vitória & 1.808 & 17,43 & $3 \cdot 334$ & 1,71 \\
\hline $\begin{array}{l}\text { Total Municípios } \\
\text { Produtores }\end{array}$ & 10.345 & 99,73 & 173.979 & 89,41 \\
\hline Demais municípios & 28 & 0,27 & 20.608 & 10,59 \\
\hline $\begin{array}{l}\text { Total Municípios } \\
\text { do ES }\end{array}$ & 10.373 & 100,00 & 194.587 & 100,00 \\
\hline
\end{tabular}

Fonte: ANP (2011).

O estimador DD permite isolar o efeito do tratamento (receitas de royalties) sobre a variável dependente, controlando-se para todas as outras possíveis causas, sem a necessidade de identificar todas as covariadas possíveis. O município $i$ pertencerá ao grupo de tratamento $(j=T)$ ou ao grupo de controle $(j$ $=C$ ) conforme seja produtor ou não de petróleo e, consequentemente, receba mais ou menos royalties.

A abordagem aqui adotada baseia-se na aplicação de Kiel e McClain (1995), isto é, estamos interessados tanto no efeito do tratamento (pertencer ao grupo de municípios que abrigam instalações petrolíferas e/ou são confrontantes com poços de petróleo) como no tamanho do tratamento (isto é, o impacto do volume de recursos transferidos para o município). 
CAÇADOR, B, S.; MONTE, E. Z. Impactos das rendas petrolíferas no crescimento econômico...

Para implementar o estimador DD e isolar os efeitos dos royalties sobre o crescimento dos PIBs per capita municipais, estimou-se o seguinte modelo:

$$
y_{i t}=\alpha+\alpha_{1} d_{t}+\alpha_{2} d^{j}+\beta_{1} d_{t}^{j}+\beta_{2} d_{t}^{j} x_{i}+\varepsilon_{i t}
$$

onde: é a taxa de crescimento do PIB per capita do município $i$ em no período $t$; , variável dummy que é igual a 1 se o município é observado após o tratamento $(t=1)$ e zero caso contrário; , dummy que é igual a 1 se $\mathrm{t}=1 \mathrm{e} \mathrm{J}=\mathrm{T}$, e zero caso contrário, indicando o efeito dos royalties nos municípios produtores; , volume de royalties per capita recebidos pelas cidades. $\mathrm{O}$ efeito tratamento nas cidades produtoras é mensurado por $\beta_{1}$ e $\beta_{2}$.

Tomando a primeira diferença em (1), obtém-se a forma funcional testável para o modelo:

$$
\Delta y_{i t}=y_{i 1}-y_{i 0}=\alpha_{1}+\beta_{1} d_{t}^{j}+\beta_{2} x_{i}+\varepsilon_{i t}
$$

em que: a constante $\alpha_{1}$ testa possíveis mudanças no padrão de crescimento das cidades como um todo entre $t=0$ e $t=1$; , dummy que indica se o município é produtor ou não de petróleo e gás; coeficiente $\beta_{1}$ captura possíveis diferenças nos padrões de crescimento dos municípios produtores, enquanto o $\beta_{2}$ mensura se o volume de royalties tem algum impacto significativo no PIB per capita local.

As variáveis "royalties per capita" " "PIB per capita" estão a preços constantes de 2000, deflacionadas pelo IPCA. Os dados foram coletados do IBGE (2011) e da ANP (2011).

A Tabela 2 resume as estatísticas descritivas das variáveis utilizadas no estudo. Como se pode observar, há uma grande variabilidade no volume de receitas de royalties entre os municípios não-produtores (grupo de controle) e produtores (grupo de tratamento).

\subsection{Resultados}

Neste item são apresentados os resultados referentes à estimativa realizada a partir do método DD. Conforme a tabela 3 mostra, a constante $\alpha_{1}$ foi significativa e positiva, indicando que após 2005 houve uma expansão generalizada (média de 13,3\%) das taxas de crescimento dos PIBs per capita municipais. De maneira diferente, a estimativa obtida para $\beta_{1}$ foi negativa e não significativa, ou seja, não se pode afirmar que as cidades produtoras de petróleo (grupo de tratamento) tiveram crescimento médio superior as demais cidades capixabas entre 2000 e 2009. Nessa linha, o efeito tratamento $\left(\beta_{2}\right)$ foi negativo e não 
CAÇADOR, B, S.; MONTE, E. Z. Impactos das rendas petrolíferas no crescimento econômico...

significativo, isto é, os royalties não impactaram o crescimento do PIB per capita dos municípios espírito-santenses. ${ }^{7}$

TABELA 2: ESTATÍSTICAS DESCRITIVAS

\begin{tabular}{l|r|r|r|r}
\hline \multirow{2}{*}{ Variáveis } & \multicolumn{2}{c|}{ Não-produtores } & \multicolumn{2}{c}{ Produtores } \\
\cline { 2 - 5 } & \multicolumn{1}{c|}{ Média } & \multicolumn{1}{c}{ D.P. } & \multicolumn{1}{c}{ Média } & \multicolumn{1}{c}{ D.P. } \\
\hline PIB per capita 2000 & $4.588,42$ & $1.195,69$ & $9.478,16$ & $7.132,23$ \\
PIB per capita 2004 & $4.933,38$ & $1.639,05$ & $12.527,99$ & $9.725,60$ \\
Crescimento 2000-2004 (\%) & 1,27 & 3,78 & 4,82 & 4,64 \\
PIB per capita 2005 & $7 \cdot 327,44$ & $2.618,60$ & $20.971,44$ & $18.993,71$ \\
PIB per capita 2009 & $13.058,52$ & $3.910,67$ & $38.841,75$ & $39.873,81$ \\
Crescimento 2005-2009(\%) & 12,57 & 3,38 & 12,07 & 6,59 \\
Royalty per capita 2000 & 0,03 & 0,01 & 10,52 & 16,46 \\
Royalty per capita 2001 & 0,02 & 0,01 & 16,58 & 30,65 \\
Royalty per capita 2002 & 0,02 & 0,01 & 17,44 & 39,40 \\
Royalty per capita 2003 & 1,68 & 0,81 & 58,27 & 101,60 \\
Royalty per capita 2004 & 1,78 & 0,86 & 118,00 & 260,88 \\
Royalty per capita 2005 & 3,05 & 1,45 & 149,99 & 316,39 \\
Royalty per capita 2006 & 22,59 & 10,67 & 329,86 & 575,62 \\
Royalty per capita 2007 & 32,47 & 15,38 & 357,76 & 652,42 \\
Royalty per capita 2008 & 45,13 & 21,21 & 727,56 & $1.963,51$ \\
Royalty per capita 2009 & 30,56 & 14,40 & 858,96 & $2.682,46$ \\
\hline
\end{tabular}

Fonte: elaboração própria, com base nos dados do IBGE (2011) e da ANP (2011).

Nota: D.P. significa desvio-padrão.

Portanto, de maneira similar a que foi constatada por Postali (2007) para os municípios brasileiros, do Rio de Janeiro, do Rio Grande do Norte e da Bahia, os resultados permitem indicar a manifestação de um fenômeno análogo à maldição dos recursos naturais ${ }^{8}$. Em outras palavras, as evidências econométricas aqui apresentadas permitem afirmar que as localidades capixabas que mais receberam royalties não apresentaram desempenho superior em termos de crescimento do PIB no período 2000-2009.

Uma possível explicação para isso é que, apesar do expressivo crescimento do repasse de royalties para os municípios capixabas como um todo nos últimos anos, o seu valor per capita ainda seja relativamente baixo. No ano de 2009, por exemplo, os royalties per capita das cidades espírito-santenses

7 Foram feitos testes para verificar se os resíduos apresentam distribuição normal - teste de Jarque-Bera (JB) -, ausência de autocorrelação - teste Breusch-Godfrey (BG) -, ausência de heterocedasticidade - teste de White - e se o modelo está bem especificado - teste RESET de Ramsey -, e nenhum problema foi constatado na estimativa. 8 Sobre o tema da maldição dos recursos naturais, ver, por exemplo, Sachs e Warner (2001). 
CAÇADOR, B, S.; MONTE, E. Z. Impactos das rendas petrolíferas no crescimento econômico...

equivaliam a apenas $36 \%$ do auferido pelas fluminenses e $46 \%$ das baianas. Destaca-se que os grandes impactos que ocorrerão em território capixaba com a exploração da camada pré-sal podem contribuir para um incremento ainda maior das rendas petrolíferas, desde que mantidos os atuais critérios de distribuição9 .

TABELA 3: RESULTADOS DA ESTIMAÇÃO

\begin{tabular}{|c|c|c|c|c|}
\hline Variáveis & Coeficientes & Erro-padrão & Valor t & P-valor \\
\hline Constante $\left(\alpha_{1}\right)$ & $13,33351^{* * *}$ & 3,491864 & 3,818450 & 0,0003 \\
\hline Intercepto $\left(\beta_{1}\right)$ & $-3,36710^{\mathrm{ns}}$ & 2,034978 & $-1,654613$ & 0,1022 \\
\hline $\begin{array}{l}\text { Ln royalties per } \\
\text { capita }\left(\beta_{2}\right)\end{array}$ & $-0,43008^{\mathrm{ns}}$ & 0,72114 & $-0,59638$ & 0,5527 \\
\hline $\mathrm{R}^{2}$ ajustado & \multicolumn{4}{|c|}{0,051016} \\
\hline $\begin{array}{l}\text { Significância con- } \\
\text { junta F }\end{array}$ & \multicolumn{4}{|c|}{$\mathrm{F}(3,74)=3,042823[0,053709]$} \\
\hline $\begin{array}{l}\text { Total de municí- } \\
\text { pios }\end{array}$ & \multicolumn{4}{|c|}{77} \\
\hline $\begin{array}{l}\text { Municípios do } \\
\text { grupo de controle }\end{array}$ & \multicolumn{4}{|c|}{62} \\
\hline $\begin{array}{l}\text { Municípios do } \\
\text { grupo de trata- } \\
\text { mento }\end{array}$ & \multicolumn{4}{|c|}{15} \\
\hline
\end{tabular}

Fonte: elaborado pelos autores com base nos dados da pesquisa.

Notas: 1$)^{* * *}$ significativo a $1 \%$; ns não significativo a $10 \%$; ln significa logaritmo natural.

\section{Considerações finais}

O volume de royalties recebidos pelas prefeituras capixabas passou de $\mathrm{R} \$$ 10,4 milhões, em 2000, para R \$ 194,5 milhões (corrigidos pelo IPCA de 2000), em 2009. Portanto, no período estudado no presente trabalho, as rendas petrolíferas tiveram uma expansão de 177,6\% ao ano, em média. Em valor per capita, os royalties passaram de $\mathrm{R} \$ 3,48$ para $\mathrm{R} \$ 89,18$ no mesmo espaço de tempo. Esses números mostram o quão relevante tem se tornado essa questão para os municípios espírito-santenses nos últimos anos, bem como quão importante é avaliar os seus impactos econômicos.

Dessa maneira, estimou-se um modelo empírico objetivando avaliar, utilizando a técnica de diferenças-em-diferenças, se as participações governamentais incentivaram o crescimento dos PIBs per capita das cidades produtoras de petróleo entre 2000 e 2009.

9 Sobre os impactos econômicos da exploração da camada pré-sal no Espírito Santo, ver Haddad e Giuberti (2010). 
Os pontos mais importantes são:

i) a estimativa não se mostrou estatisticamente significante para a relação entre crescimento do PIB per capita e as cidades produtoras de petróleo;

ii) logo, foi possível concluir pela existência do fenômeno da maldição dos recursos naturais nessas cidades capixabas produtoras de petróleo.

Finalizando, algumas recomendações gerais em termos de políticas públicas podem ser feitas, tomando como base Pessôa (2010). De forma resumida, o autor defende dois princípios básicos para o uso da melhor forma possível dos recursos provenientes da receita petrolífera: i) a renda petrolífera constitui uma riqueza e como tal deve ser tratada, ou seja, o poder público deve ter cautela ao decidir empregar a renda petrolífera em um programa específico; ii) embora haja fortes evidências na literatura que rendas oriundas de recursos naturais não são eficientemente empregadas, o mesmo não pode categoricamente afirmado para os municípios capixabas, conforme análise anterior, mas de qualquer forma há o entendimento de que a transparência constitui o instrumento mais poderoso para combater essas consequências indesejadas da abundância de recursos naturais. Por isso, devem ser criados mecanismos e instituições que elevem o controle social sobre a renda petrolífera.

\section{Referências Bibliográficas}

Agência Nacional do Petróleo - ANP (2011). "Estatísticas de produção de petróleo e gás natural e de participações governamentais no Brasil e no Espírito Santo.” Disponível em: <http://www.anp.gov.br >. Acesso em: 30 de jun. 2011.

Barbosa, D. H. (2001) “Guia dos royalties do petróleo e do gás natural. Rio de Janeiro: Agência Nacional do Petróleo (ANP). 156 p.” Disponível em: < http://www.anp. gov.br>. Acesso em: 28 jun. 2011.

Bregman, D. (2007) "Formação, distribuição e aplicação de royalties de recursos naturais: o caso do petróleo no Brasil.” Universidade Federal do Rio de Janeiro (Dissertação de Mestrado). Rio de Janeiro.

Caselli, F.; Michaels, G. (2009) “Do oil windfalls improve living standards? Evidence from Brazil”. NBER Working paper, 15550.

Costa Nova, L. (2005) “Análise do impacto social de receitas provenientes de royalties do petróleo em municípios do estado da Bahia.” Universidade de Brasília (Dissertação de Mestrado). Brasília.

Freire, S.; Magenta, M. (2011) “Bonança do petróleo não melhora cidades.” Folha de São Paulo, 31/10/2011, p. A12.

Grassi, R. A.; Caçador, S. B. (2007) “Os impactos das participações governamentais nas finanças públicas e na economia do Espírito Santo”. In: PIQUET, Rosélia; SERRA, Rodrigo. (Org.). Petróleo e Região no Brasil: o desafio da abundância. 
CAÇADOR, B, S.; MONTE, E. Z. Impactos das rendas petrolíferas no crescimento econômico...

1 ed. Rio de Janeiro: Garamond.

Haddad, E. A.; Giuberti, A. C. (2010) "Economic impacts of pre-salt on a regional economy: the case of Espírito Santo, Brazil". Sustainable Regional Growth and Development in the Creative Knowledge Economy, 2010, Jönköping, Sweden. European Congress of the Regional Science Association International.

Instituto Brasileiro de Geografia e Estatística - IBGE. (2011) "Estatísticas de PIB e população do Espírito Santo.” Disponível em: <http://www.ibge.gov.br $>$. Acesso em: 30 de jun. 2011.

Kiel, K. A.; Mcclain, K. T. (1995) "House prices during siting decision stages: the case of an incinerator from rumor through operation." Journal of Environmental Economics and Management, v. 28. pp. 241-255.

Leal, J. A.; Serra, R.V. (2002) "Notas sobre os fundamentos econômicos da distribuição espacial dos royalties petrolíferos no Brasil”. Anais do XXX Encontro Nacional de Economia (ANPEC). Nova Friburgo, Rio de Janeiro.

Macroplan. (2012) "Royalties do petróleo e desenvolvimento municipal: avaliação e propostas de melhoria." Relatório Final,junho de 2012. Disponível em: $<\underline{\text { http: } / /}$ www.macroplan.com.br>. Acesso em: 30 de ago. 2012.

Meyer, B. D. (1995) "Natural and quasi-experiments in economics.” Journal of Business and Economic Statistics. v. 13, pp. 151-161.

Ministério Público do Estado do Espírito Santo (MPES) (2011) “Ação do MPES nos municípios produtores de petróleo e gás.” Relatório Final, 2011. Disponível em: <http://www.mpes.gov.br>. Acesso em: 30 de agosto de 2012.

Navarro, C. A. S. (2003) "Royalties do petróleo: estudo do caso de Campos dos Goytacazes.” Universidade Cândido Mendes (Dissertação de Mestrado). Campos.

Pessôa, S. A. (2010) "O uso da renda petrolífera pelo Estado do Espírito Santo". In: VESCOVI, A. P. V. J.; BONELLI, R. (Org.). Espírito Santo: instituições, desenvolvimento e inclusão social. Vitória, ES: Instituto Jones dos Santos Neves, cap. 8, p. 269-292.

Postali, F.; Nishijima, M. (2011) “Distribuição das rendas do petróleo e indicadores de desenvolvimento municipal no Brasil nos anos 2000”. Estudos Econômicos, v. 41, n. 2, abril-junho de 2011.

Postali, F. (2002) "Renda mineral, divisão de riscos e benefícios governamentais na exploração de petróleo no Brasil.” Rio de Janeiro: BNDES. 120 p.

. (2007) "Efeitos da distribuição de royalties do petróleo sobre o crescimento dos municípios no Brasil.” XXXV Encontro Nacional de Economia (ANPEC). Recife, Pernambuco.

Ribeiro, E.; Teixeira, A.; Gutierrez, C. E. (2010) “Impacto dos royalties do petróleo no PIB per capita dos municípios do Estado do Espírito Santo, Brasil”. Revista Brasileira de Gestão de Negócios, v. 12, n. 34, janeiro-março de 2010.

Sachs, J.; Warner, A. (2001) “The curse of natural resources”. European Economic Review, v. 45, p. 827-838.

Secretaria do Tesouro Nacional - STN. (2011). "Estatísticas de finanças públicas de municípios do Espírito Santo.” Disponível em: <http://www.stn.fazenda.gov. br>. Acesso em: 30 de jun. 2011. 
CAÇADOR, B, S.; MONTE, E. Z. Impactos das rendas petrolíferas no crescimento econômico...

Recebido em: 21 de setembro de 2012 Aceito em: 23 de fevereiro de 2012 
CAÇADOR, B, S.; MONTE, E. Z. Impactos das rendas petrolíferas no crescimento econômico... 